\title{
Epicutaneous Immunotherapy Compared with Sublingual Immunotherapy in Mice Sensitized to Pollen (Phleum pratense)
}

\author{
Lucie Mondoulet, ${ }^{1}$ Vincent Dioszeghy, ${ }^{1}$ Mélanie Ligouis, ${ }^{1}$ Véronique Dhelft, ${ }^{1}$ \\ Emilie Puteaux, ${ }^{1}$ Christophe Dupont, ${ }^{2}$ and Pierre-Henri Benhamou ${ }^{1}$ \\ ${ }^{1}$ DBV Technologies, R\&D Department, 92220 Bagneux, France \\ ${ }^{2}$ Hôpital Necker, Gastroenterology Department, 75014 Paris, France \\ Correspondence should be addressed to Lucie Mondoulet, lucie.mondoulet@dbv-technologies.com
}

Received 19 December 2011; Accepted 4 January 2012

Academic Editors: B. M. Stadler and B. Vonakis

Copyright (C) 2012 Lucie Mondoulet et al. This is an open access article distributed under the Creative Commons Attribution License, which permits unrestricted use, distribution, and reproduction in any medium, provided the original work is properly cited.

\begin{abstract}
Background. The aim of this study was to compare the efficacy of epicutaneous immunotherapy (EPIT) to sublingual immunotherapy (SLIT) in a model of mice sensitized to Phleum pratense pollen. Methods. BALB/c mice were sensitized by subcutaneous route to pollen protein extract mixed treated for 8 weeks, using sham, EPIT, or SLIT. Measurements involved the serological response and cytokine profile from reactivated splenocytes, plethysmography after aerosol challenge to pollen, cell, and cytokine contents in the bronchoalveolar lavages (BALs). Results. After immunotherapy, sIgE was significantly decreased in the treated groups compared to sham $(P<0.001)$, whereas sIgG2a increased with EPIT and SLIT $(P<0.001$ and $P<0.005$ versus sham). Reactivated splenocytes secreted higher levels of Th2 cytokines with sham $(P<0.01)$. Penh values were higher in sham than EPIT and SLIT. Eosinophil recruitment in BAL was significantly reduced only by EPIT $(P<0.01)$. Conclusion. In this model of mice sensitized to pollen, EPIT was at least as efficient as SLIT.
\end{abstract}

\section{Introduction}

Specific immunotherapy has been used for almost a century in allergic patients to redirect inappropriate immune responses. The long-term benefits of subcutaneous immunotherapy (SCIT) were demonstrated by Durham et al. in patients with grass pollen sensitization [1]. SCIT is now considered as the reference method by the World Health Organization (WHO) and the gold standard treatment of allergy [2].

For various reasons, noninvasive routes (e.g., nasal, oral, or sublingual) have been evaluated as alternatives to subcutaneous injections [3], the sublingual route being the most widely used. Many trials have established the safety and efficacy of sublingual immunotherapy (SLIT) $[4,5]$. A model of SLIT in mice sensitized to timothy grass allergen (Phleum pratense- $\mathrm{Ph} 1 \mathrm{p}$ ) has been reported [6].

Recently, Senti et al. [7] have proposed a new method of noninvasive immunotherapy using the epicutaneous route in patients sensitized to pollen. This method is a promising alternative to the well-established SCIT and SLIT [3]. In par- allel, we communicated encouraging results of epicutaneous immunotherapy (EPIT) in children allergic to cow's milk [8] and published data of EPIT in a mice model using various allergens [9]. The latter were obtained using Viaskin, a new epicutaneous delivery system (EDS).

The purpose of the present study was to compare EPIT to SLIT with regards to the immune response they generate in mice sensitized to timothy grass pollen.

\section{Materials and Methods}

2.1. Animals and Study Design (Figure 1). Three-week-old female BALB/c mice (Charles Rivers, Lyon, France) were purchased and housed under standard animal husbandry conditions. Mice were acclimated for 1 week before immunization. After a phase of sensitization validated by an increase in specific IgE (sIgE), mice were randomly allocated to 3 groups of 10 animals and treated during 8 weeks: (1) EPIT, treated by epicutaneous immunotherapy (EPIT $100 \mu \mathrm{g}$ ), (2) SLIT, treated by sublingual immunotherapy 


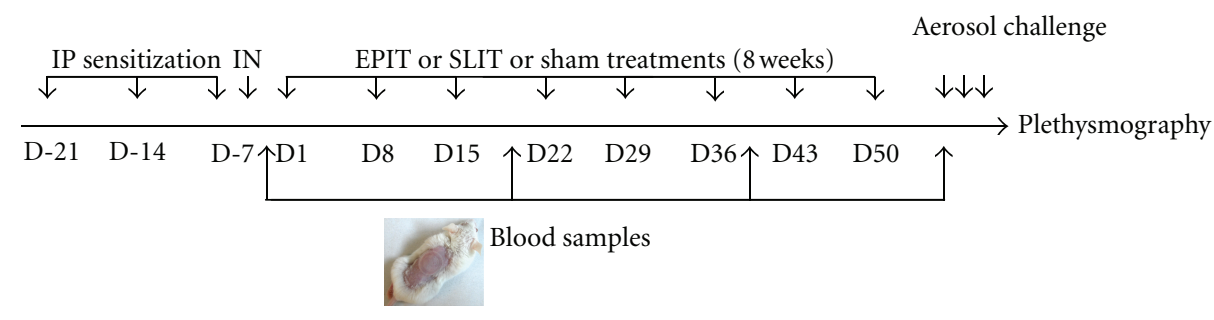

Figure 1: Study design. Mice were sensitized to pollen proteins by 3 subcutaneous injections, with aluminium hydroxide as adjuvant, separated at 1-week interval. Immunotherapy was conducted during 8 weeks with one treatment per week: one sublingual administration or one 48-h application of Viaskin epicutaneous delivery system. Blood was sampled before immunotherapy (D0) to validate the phase of sensitization and during immunotherapy (D21, D38, D63).

(SLIT $100 \mu \mathrm{g}$ ), or (3) sham treated by empty EDS and solution vehicle used in SLIT. Ten naive mice (not sensitized and not treated) were also included.

Seven days after the end of the treatment, animals were challenged for 3 days with grass pollen aerosol. Animals were then submitted to evaluation of airway hyperresponsiveness (AHR) by plethysmography. Finally, all animals were submitted to a bronchoalveolar lavage (BAL) for cytological and immunological analyses and to a culture of spleen cells for cytokine analysis.

Skin preparations before EDS application or sublingual administrations were all performed under general anesthesia by Ketamine (Imalgen1000, Merial) $(100 \mathrm{mg} / \mathrm{kg}$ body weight) and Xylazine (Rompun, Bayer) $(10 \mathrm{mg} / \mathrm{kg}$ body weight). BAL was performed under general anesthesia by intraperitoneal administration of pentobarbital (Nembutal, Sanofi Santé animale, CEVA) (50 mg/kg body weight), and venipuncture was performed under general anesthesia by isoflurane (Isoflurane Belamont, Nicholas Piramal India).

All experiments were performed according to the European Community rules on animal care with permission 92 305 from the French Veterinary Services.

2.2. Immunization. Mice were sensitized to pollen by means of three subcutaneous injections at one week interval on the back of the neck with $10 \mu \mathrm{g}$ of Phleum pratense pollen protein extract (ALK, Varennes en Argonne, France) and $1 \mathrm{mg}$ of aluminum hydroxide (Sigma, Saint Quentin Fallavier, France) using a protocol adapted from Wiedermann et al. Blood specific IgEs were quantified 10 days after the last injection to confirm sensitization. Naïve mice received $200 \mu \mathrm{L}$ of sterile solution containing $0.9 \% \mathrm{NaCl}$ by subcutaneous injections according to the same scheme.

\subsection{Treatment}

2.3.1. Epicutaneous Immunotherapy (EPIT). EPIT was performed using an original epicutaneous delivery system (EDS) (Viaskin, DBV Technologies, Paris France) consisting of a central transparent polyethylene membrane $(11 \mathrm{~mm}$ in diameter) surrounded by a clear double-sided adhesive polypropylene film to maintain the chamber on the skin. Dry powder of pollen extract is maintained on the backing by electrostatic forces. An occlusive chamber is created on the skin that rapidly generates moisture and releases the allergen from its support. The allergen is then absorbed by the skin where it interacts with epidermal immune cells. The use of this technology as diagnosis purpose (Diallertest) was previously published [10].

EDS with $100 \mu \mathrm{g}$ of pollen protein extract (containing $5 \mu \mathrm{g}$ of Ph1 p 5) was applied for $48 \mathrm{~h}$ to the back of mice, once a week during 8 weeks. Twenty-four (24) hours before application, skin was shaved with an electric clipper and depilatory cream was applied. This technique does not modify the barrier properties of the skin. This was demonstrated in a previous experience by the absence of change in the transepithelial water loss (TEWL), as compared with hairless mice $\left(6.45 \pm 1.22\right.$ versus $6.63 \pm 1.49 \mathrm{~g} / \mathrm{h} / \mathrm{m}^{2}$, $\left.\mathrm{ns}\right)$.

2.3.2. Sublingual Immunotherapy (SLIT). Once a week during 8 weeks, mice of the SLIT group received $5 \mu \mathrm{L}$ of a homogeneous preparation of $100 \mu \mathrm{g}$ of pollen protein extract (containing $5 \mu \mathrm{g}$ of Ph1 p 5, the optimal SLIT dose described by Brimnes et al. in their murine model [6]) in PBS administered sublingually under the tongue. Similarly, mice of EPIT and Sham groups received $5 \mu \mathrm{L}$ of phosphate-buffered saline (PBS). To increase their viscosity, the sublingual solutions were prepared with $1.2 \%$ of carboxymethylcellulose (CMC) (w/v) (Sigma, Saint Quentin Fallavier, France). To prevent the animals from swallowing the solution (allergen or PBS), weekly administrations were all performed under anesthesia with ketamine and xylazine.

During general anesthesia, the distribution of sublingually applied solutions was investigated with additional mice, as previously described by Brimnes et al. [6] using 1\% Evans Blue solution in PBS with CMC. The mice were sacrificed $5 \min (n=6), 15 \min (n=6)$, and $30 \min (n=6)$ after the administration of the dye and the distribution evaluated in the sublingual tissue, esophagus, and stomach by visual inspection and extraction of tissue in acetone/Zephiran solution as described by Caster et al. [11] followed by measurement of absorption at $620 \mathrm{~nm}$ in microtiter plate using Multiscan Ex plate reader (Thermo Scientific, CergyPontoise, France). Two mice without administration of dye were also evaluated as negative controls. Thirty minutes after sublingual administration, dye was only detectable in the sublingual tissue but not in the esophagus and in the stomach. The absorbance in sublingual tissues decreased 
from 0.41 (at $5 \mathrm{~min}$ ), 0.22 (at $15 \mathrm{~min}$ ) to 0.15 (at $30 \mathrm{~min}$ ) compared to $0.04(P<0.001)$ in control sublingual tissues.

2.3.3. Sham and Control Groups. During the immunotherapy period, the Sham group received both an empty EDS and a sublingual administration of PBS and carboxymethylcellulose $(1.2 \%, \mathrm{w} / \mathrm{v})$ on a weekly basis, following the same procedures as for the EPIT and SLIT groups. The control group was not sensitized and not treated.

2.4. Specific IgE, IgG1, and IgG2a in Blood. Blood was collected from the retroorbital venous plexus 10 days after sensitization (D0) and during immunotherapy (D21, D38, D63).

Specific antibodies were quantified using a quantitative ELISA developed in-house according to the 2001 FDA guidelines. Briefly, microtiter plates were coated with $100 \mu \mathrm{L}$ per well of $5 \mu \mathrm{g} / \mathrm{mL}$ pollen protein extract solution. Serial dilutions of $50 \mu \mathrm{L}$ of each serum were dispensed per well and incubated for $24 \mathrm{~h}$ at $+4^{\circ} \mathrm{C}$. An anti-mouse IgE, IgG1, or IgG2a antibody labeled with phosphatase alkaline (Serotec, Oxford, England) was used as a tracer. P-nitrophenyl phosphate (pNPP_-Sigma, France) was used as the enzyme substrate. Specific IgE, IgG1, and IgG2a were quantified by comparison with concentration-response curves obtained with a total IgE, IgG1, or IgG2a assay performed under identical conditions using a solid phase coated with an anti-mouse IgE, IgG, or IgG2a antibody (Serotec, Oxford, England). The cross-reactivity of secondary antibodies with immunoglobulins was less than $4 \%$ for all the antibodies and less than $0.1 \%$ for anti-IgG1 and anti-IgG2a antibodies against purified IgE.

2.5. Cell Culture. After BAL, mice were sacrificed and spleens teased into a single-cell suspension and washed three times in RPMI-1640 (Dutcher, Brumath, France). After lysis of the red blood cells ( $180 \mathrm{nM} \mathrm{NH} \mathrm{NH}_{4} \mathrm{Cl} 17 \mathrm{mM} \mathrm{Na} \mathrm{NaDTA}_{2}$ and several washes, splenocytes were resuspended in RPMI supplemented with 10\% FCS, $2 \mathrm{mM}$ L-glutamine, 100U penicillin, and $100 \mu \mathrm{g} / \mathrm{mL}$ streptomycin. Cells were counted, adjusted to $3 \times 10^{6}$ cells $/ \mathrm{mL}$ in each well of a 24 -well flatbottomed culture plate (Nunc), and stimulated by Phl p extract $(100 \mu \mathrm{g} / \mathrm{mL})$ or by its solvent (RPMI supplemented with FCS, L-glutamine, penicillin, and streptomycin). The cells were cultured in presence or not of Phleum pratense extract $\left(100 \mu \mathrm{g} / \mathrm{mL}\right.$ per well) for $72 \mathrm{~h}$ at $37^{\circ} \mathrm{C}$ and $5 \% \mathrm{CO}_{2}$. Supernatants were then removed and stored at $-80^{\circ} \mathrm{C}$ until further assay.

2.6. Cytokine Levels and Cell Composition in Blood, BAL Fluid, and Cell Culture Supernatants. Blood samples for cytokine analyses were collected in anesthetized mice the day after AHR measurement. Cytokines and cells were measured in BAL fluids 24 and 48 hours after the last aerosol challenge. Cells were characterized using the cytospin slides stained with DiffQuick (Baxter Dade AG, Duedingen, Switzerland).

In supernatants of cell cultures, cytokines were assayed using the BioPlex Cytokine Assay according to the manufacturer's recommendations (Bio-Rad, Marnes La Coquette, France).
2.7. Airway Hyperresponsiveness (AHR) Measured by WholeBody Plethysmography. Whole-body plethysmography was performed in a closed chamber allowing recording the pressure fluctuations during the breathing cycle of mice. "Enhanced pause" (Penh) was calculated as previously described by Hamelmann et al. [12] from the box pressure recorded during inspiration and expiration, and the timing comparison of early and late expiration. Penh corresponds to PEP/PIP, where PEP is peak expiratory pressure and PIP is peak inspiratory pressure. Mice were challenged with pollen by 30 minutes of aerosol ( $10 \mathrm{~mL}$ of $1 \%$ pollen extract in $0.9 \%$ $\mathrm{NaCl}$ ) during 3 consecutive days. Pressures were measured 24 hours after the challenge, and Penh values were calculated prior to and during $10 \mathrm{~min}$ after aerosol of various doses of methacholine (Sigma-Aldrich, Stonheim, Germany). For each mouse, Penh values were plotted against methacholine concentration (from 0 to $40 \mathrm{mg} / \mathrm{mL}$ ) and the area under the curve (AUC) was calculated [13].

2.8. Statistical Analysis. The GraphPad Prism Software 5.0 (San Diego, CA, USA) was used for statistical analysis $(n=$ 10-20 mice per group). Results are expressed as mean \pm standard deviation (SD). Antibody responses as well as cell and cytokine data were analyzed using analysis of variance (ANOVA) and Tukey's test for intergroup comparisons. The raw data of Penh values were analyzed using the nonparametric Mann-Whitney $U$ test. Penh data were also analyzed using the complete methacholine dose-response curve. For each mouse, Penh was plotted against methacholine concentration (from 0 to $40 \mathrm{mg} / \mathrm{mL}$ or from 0 to $10 \mathrm{mg} / \mathrm{mL}$ ) and the AUC was calculated. Then, data were analyzed using analysis of variance (ANOVA) and Dunnett's test when comparing treated mice with controls and using ANOVA and Tukey's test when comparing all the groups with each other.

\section{Results}

3.1. Serological Response to Sensitization and Immunotherapy (Table 1). At the end of the sensitization period (D0), the detection of serum sIgE, sIgG1, and sIgG2a in all but the control group confirmed the efficacy of the sensitization protocol.

At the end of treatment (D63), sIgE levels remained unchanged in the treated groups but further increased in the Sham group $(P<0.001$ versus EPIT or SLIT). sIgG1 increased similarly with EPIT and SLIT $(P<0.05$ versus Sham). sIgG2a increased only at the end of the treatment with EPIT or SLIT (resp., $P<0.001$ and $P<0.05$ versus sham). The sIgG2a increase was higher with EPIT than with SLIT $(P<0.05)$.

3.2. Cytokines Secreted by Reactivated Spleen Cells after Immunotherapy (Figure 2). The T-cell response was assessed by measuring the ex vivo allergen-specific cytokine production of spleen cells from the 4 groups of mice. Spleen cells reactivated with buffer did not secrete significant amounts of cytokines (data not shown), and, in a preliminary study, the optimal dose was determined by performing a dose-response 

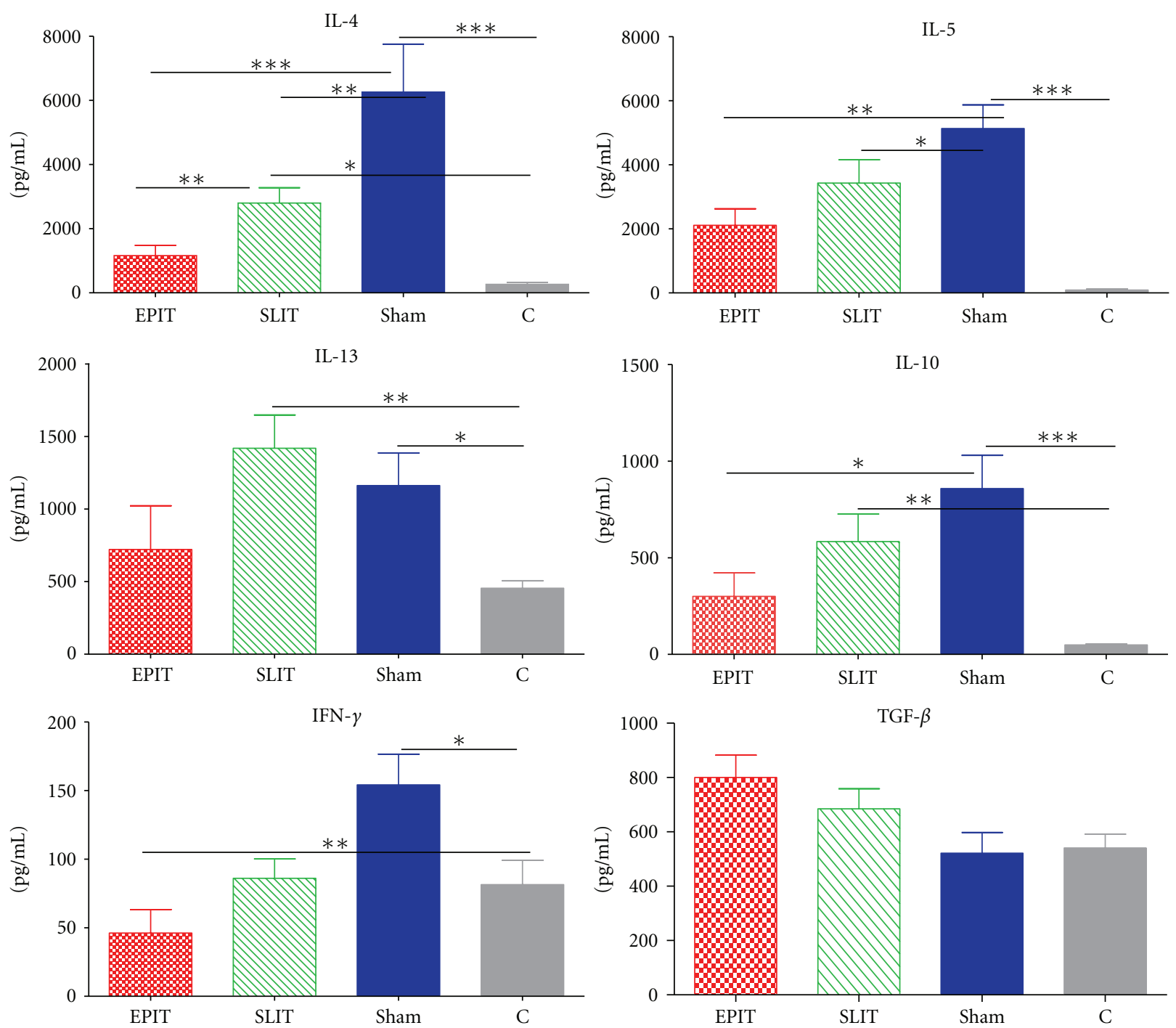

FIGURE 2: Ex vivo cytokine production of spleen cells restimulated with $\mathrm{Phl} p$ extract $(100 \mu \mathrm{g} / \mathrm{mL})$. Treatment groups were EPIT (epicutaneous immunotherapy), SLIT (sublingual immunotherapy), sham (sensitized not treated), and C (control, not sensitized, and not treated). ${ }^{*} P<0.05,{ }^{* *} P<0.01,{ }^{* * *} P<0.001$.

curve $(10,50$, and $100 \mu \mathrm{g} / \mathrm{mL}$ of Phleum pretense extract). Spleen cells from all sensitized mice restimulated with $\mathrm{Phl} p$ extract secreted higher amounts of Th2 cytokines (IL-4, IL-5, and IL-10) than those of controls $(P<0.05$ to $P<0.001)$. Only EPIT was associated with lower levels of INF- $\gamma$ than Controls $(P<0.01)$. As compared with sham, spleen cells from EPIT and SLIT mice secreted lower amounts of IL-4 (resp., $P<0.001$ and $P<0.01$ ) and IL-5 (resp., $P<0.01$ and $P<0.01$ ). EPIT downregulated IL- 4 more than SLIT did $(P<0.01)$ and was able to decrease IL-10 $(P<0.05$ versus Sham), which was not observed with SLIT. Finally, the IL$4 / \mathrm{INF} \gamma$ ratio was lower with EPIT $(25 \pm 1.3)$ than with SLIT $(30 \pm 1.03, P<0.05)$ or sham $(46 \pm 3.0, P<0.05)$. The IL$4 /$ IFN $\gamma$ ratio in the SLIT group was not significantly different from that observed in the sham group.

3.3. Immune Cells and Cytokines in Bronchoalveolar Lavage. EPIT decreased the number of eosinophils in BAL, as com- pared to sham and SLIT (resp., $P<0.01$ and $P<0.05$ ) (Figure 3). EPIT and SLIT both decreased dramatically IL4 and IL-5 but not IFN- $\gamma(P<0.001$, data not shown $)$ in the BAL fluid (Figure 4) and serum (data not shown).

3.4. Plethysmography Analysis. The airway hyperresponsiveness (AHR) to methacholine exposure was measured by plethysmography after 3 days of aerosol challenge. The sham group responded to increasing doses of methacholine with marked AHR; EPIT and SLIT significantly decreased AHR (Figure 5(a)). At the highest dose of methacholine $(40 \mathrm{mg} / \mathrm{mL})$, mean Penh values for Sham, EPIT, SLIT, and controls were, respectively, at 17.9 $\pm 3.8,6.2 \pm 1.1(P<0.001$ versus sham), $7.9 \pm 4.8(P<0.001)$, and $4.3 \pm 1.1(P<$ $0.001)$. EPIT and SLIT also decreased Penh AUC values, as compared with sham $(P<0.001)$ (Figure 5(b)). Interestingly, EPIT induced a homogenous AHR decrease in all mice. With SLIT, 2 mice did not respond to treatment and did not 
TABLE 1: Quantification of specific IgE (ng/mL), IgG1, and IgG2a $(\mu \mathrm{g} / \mathrm{mL})$ for EPIT, SLIT, sham, and Control (C) groups.

\begin{tabular}{|c|c|c|c|c|c|}
\hline \multicolumn{2}{|c|}{ Pollen-specific antibodies } & EPIT & SLIT & Sham & $\mathrm{C}$ \\
\hline \multirow{4}{*}{$\operatorname{IgE}$} & D0 & $57( \pm 9.8)$ & $48( \pm 1.7)$ & $84( \pm 10.5)$ & Und \\
\hline & D21 & $86( \pm 8.7)$ & $88( \pm 10.4)$ & $79( \pm 7.1)$ & Und \\
\hline & D38 & $55( \pm 1.7)$ & $138( \pm 43.4)$ & $88( \pm 12.4)$ & Und \\
\hline & D63 & $71( \pm 9.0)^{* * *}$ & $58( \pm 4.5)^{* * *}$ & $137( \pm 11.9)$ & Und \\
\hline \multirow{4}{*}{ IgG1 } & D0 & $1.1( \pm 0.15)$ & $1.1( \pm 0.1)$ & $1.3( \pm 0.2)$ & Und \\
\hline & D21 & $18.2( \pm 1.36)$ & $10.6( \pm 0.8)$ & $7.7( \pm 1.3)$ & Und \\
\hline & D38 & $57.1( \pm 3.6)$ & $37.5( \pm 4.9)$ & $10.3( \pm 2.1)$ & Und \\
\hline & D63 & $113.6( \pm 13.2)^{* * *}$ & $75.8( \pm 20.2)^{* * *}$ & $18.0( \pm 3.6)$ & Und \\
\hline \multirow{4}{*}{$\operatorname{IgG} 2 \mathrm{a}$} & D0 & $0.06( \pm 0.001)$ & $0.01( \pm 0.002)$ & $0.02( \pm 0.002)$ & Und \\
\hline & D21 & $0.03( \pm 0.006)$ & $0.05( \pm 0.011)$ & $0.05( \pm 0.032)$ & Und \\
\hline & D38 & $0.03( \pm 0.012)$ & $0.08( \pm 0.042)$ & $0.03( \pm 0.011)$ & Und \\
\hline & D63 & $0.14( \pm 0.008)^{\dagger}, * * *$ & $0.09( \pm 0.031)^{*}$ & $0.001( \pm 0.001)$ & Und \\
\hline
\end{tabular}

Statistical comparison, EPIT versus SLIT: ${ }^{\dagger} P<0.05$.

Statistical comparison, EPIT, or SLIT versus Sham: ${ }^{*} P<0.05, * * P<0.01,{ }^{* * *} P<0.001$.

C, control; EPIT: epicutaneous immunotherapy; IgE: immunoglobulin E; IgG1: immunoglobulin G1; IgG2a: immunoglobulin G2a; SLIT: sublingual immunotherapy; Und: undetectable.

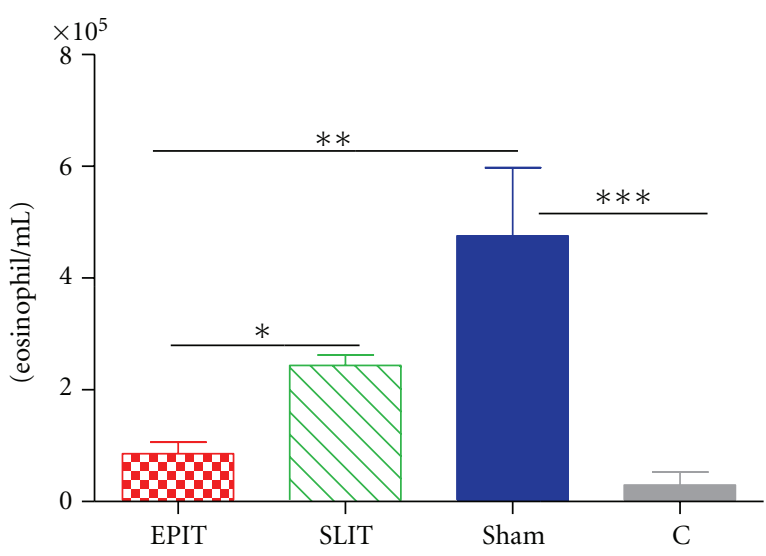

FIgURE 3: Recruitment of eosinophils in the BAL fluid measured $48 \mathrm{~h}$ after the last aerosol challenge. Treatment groups were EPIT (epicutaneous immunotherapy), SLIT (sublingual immunotherapy), sham (sensitized not treated), and $C$ (control, not sensitized and not treated). ${ }^{*} P<0.05,{ }^{* *} P<0.01,{ }^{* * *} P<0.001$.

improve AHR. As a result, whereas AUC values following EPIT were identical to those of control mice, those following SLIT remained higher $(P<0.05)$.

\section{Discussion}

These data confirm the results obtained in previous studies using the same protocol in sensitized mice treated with comparable efficacy with EPIT or SCIT [9].

In the present study, validated methods of sensitization were used $[6,14,15]$. This was here confirmed by the detection of sIgE, sIgG1, and sIgG2 in each sensitized group, as previously reported with the same protocol [9]. Increased Penh values at every dosage of methacholine in the sham group confirmed the accuracy of this model of bronchial hyperresponsiveness and were consistent with the literature [12].
Due to the high levels of specific IgG1 and to verify that the ELISA method used did not underestimate specific IgE levels, a reverse enzyme allergosorbent assay was performed in which total serum IgE antibodies were first captured by immobilized anti-mouse IgE monoclonal antibodies [9]. Results of this experiment performed after EPIT in peanutsensitized mice were comparable to those of ELISA.

To date, the in vivo measurement of respiratory function in mice is based on both noninvasive and invasive approaches. Whole body plethysmography is noninvasive and has been used in various mouse models of allergy $[16,17]$. It allows recording the pressure fluctuations that occur during the breathing cycle of mice and measures a single parameter called Penh. In a previous study comparing EPIT and SCIT in mice sensitized to peanuts, we performed both whole body plethysmography and intratracheal resistance/compliance measurements. Results appeared perfectly similar with the two methods of investigation [18]. Hence, for ethical reasons, only plethysmography was here evaluated.

EPIT was performed using Viaskin, a new epicutaneous delivery system (EDS) promoting, without any adjuvant, dissemination of allergens in the thickness of the stratum corneum, in contact with the immune cells of the epidermis [19]. By contrast with previous studies, the use of Viaskin allowed performing EPIT without requiring any skin stripping [20-22]. We have already demonstrated the efficacy of this model of EPIT with regard to four clinically relevant allergens, 2 respiratory allergens (Dactylis glomerata pollen and house dust mite) and 2 food allergens (peanut and ovalbumin) [9]. The current study thus extends the application of EPIT using Viaskin to another allergy to pollen (i.e., Phleum pratense) and clearly states the equivalent efficacy of EPIT to SLIT method.

For SLIT, despite extensive investigations in clinical practice [23], very few animal models have been published. The practical difficulties of developing a suitable animal model probably explain the low number of studies in this area. The only two studies comparable to the present one, and 


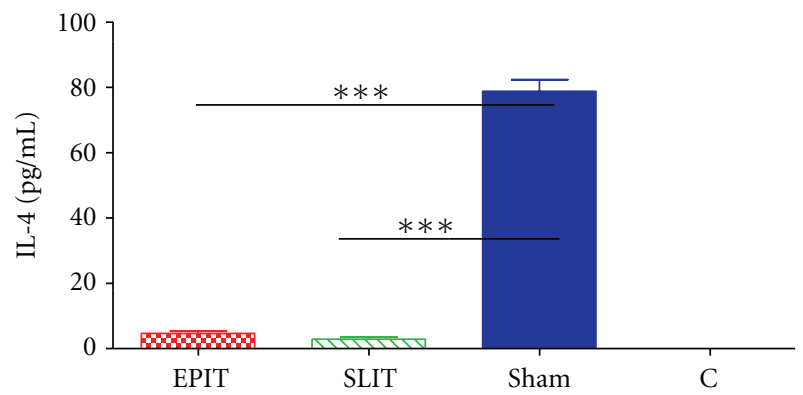

(a)

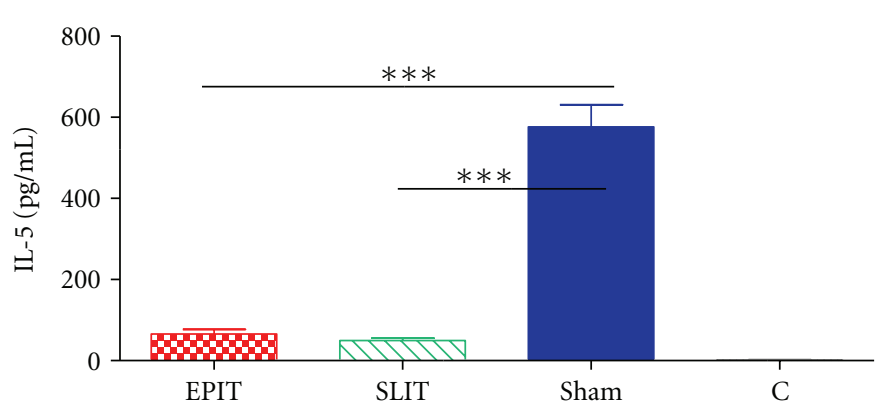

(b)

FIGURE 4: Th2 cytokines (IL-4 (a) and IL-5 (b)) measured in the BAL fluid. After the sensitization and treatment periods, mice were challenged by aerosol during 3 consecutive days. Forty-eight hours after the last challenge, BAL fluids were collected. Treatment groups were EPIT (epicutaneous immunotherapy), SLIT (sublingual immunotherapy), sham (sensitized not treated), and C (control, not sensitized, and not treated). ${ }^{*} P<0.05,{ }^{* *} P<0.01,{ }^{* * *} P<0.001$.

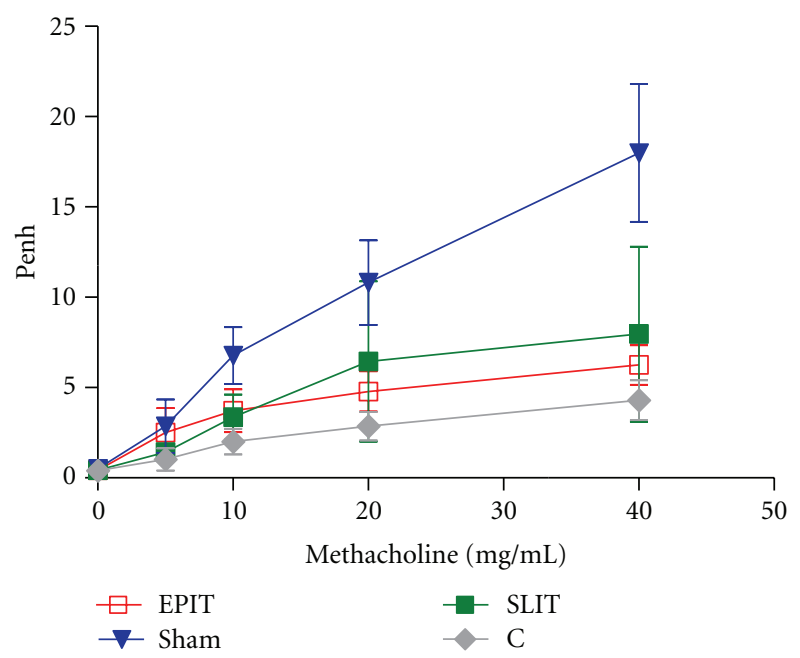

(a)

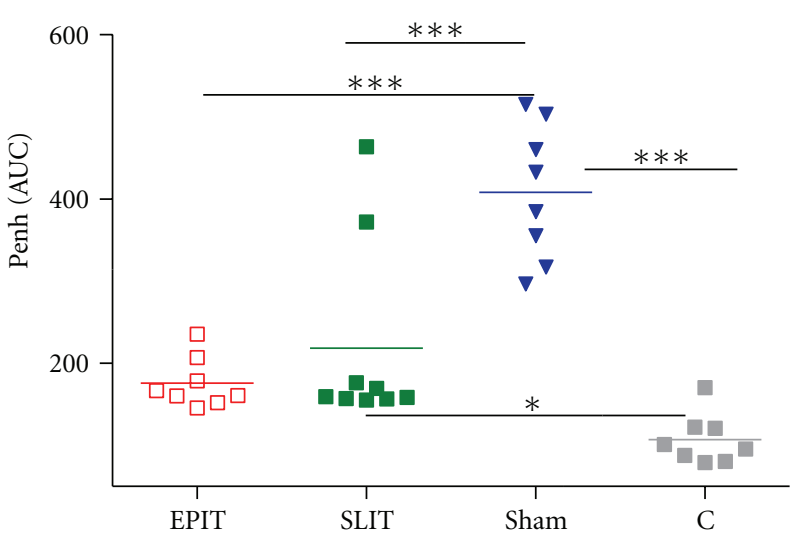

(b)

FIGURE 5: Airway hyperresponsiveness after immunotherapy. Mice were exposed to increasing doses of methacholine the day following the last 30-minute aerosol challenge: (a) dose-response curves and (b) individual area under the curve (AUC) calculated from data of graph (a) Treatment groups were EPIT (epicutaneous immunotherapy), SLIT (sublingual immunotherapy), sham (sensitized not treated), and C (control, not sensitized, and not treated). ${ }^{*} P<0.05,{ }^{* *} P<0.01,{ }^{* * *} P<0.001$.

published to date used a different procedure for the sublingual administration of the allergen. To prevent animals from swallowing the allergen solution, Brimnes et al. [6] were holding them by the scruff of the neck during 20 seconds after application of the allergen under the tongue. In the other study, the allergen was absorbed in a mucoadhesive solution, which was fixed under the tongue [24]. In the current study, the viscosity of the solution was increased using CMC in addition to pollen proteins and every sublingual administration of Phlp was performed under general anesthesia during a long period (from 30 to 60 minutes). As general anesthesia depresses swallowing [25], it ensures optimal contact of the mucosa with allergen. Using Evans Blue dye combined with CMC, dye appeared to be only detectable in sublingual tissues until 30 minutes after sublingual treatment contrary to the model of Brimnes et al. [6], where dye was also found inside the stomach. The immune response to the sublingual treatment, globally similar to that of other studies, and in some points to EPIT in the current study, confirms the efficacy of this route of administration.

EPIT and SLIT were both overall efficient in this stud$y$ but slight differences were observed according to the technique used. The dramatic increase in sIgE levels observed during the 8 weeks of sham treatment in sham was equally suppressed by EPIT and by SLIT. In accordance with our previous results [9], EPIT and SLIT increased IgG2a, the mice equivalent of humans IgG4, but this increase was significantly higher with EPIT than with SLIT. This serological response compares with the clinical data since it is well established that SLIT treatment leads to a systemic 
increase of sIgG4 whereas sIgEs increase or remain stable [26].

EPIT decreased $\mathrm{T}_{\mathrm{H}}$ 2-related cytokines (IL-4 and IL-5) in serum and BAL, as well as the IL-4/INF- $\gamma$ ratio in spleen cell culture supernatant. Overall, these changes reflect the switch of the immune response from a $\mathrm{T}_{\mathrm{H}} 2$ to a balanced $\mathrm{T}_{\mathrm{H}} 2 / \mathrm{T}_{\mathrm{H}} 1$ profile. However, as compared to SLIT, EPIT seemed to induce a stronger reduction of the $\mathrm{T}_{\mathrm{H}} 2$ response with a sharper decrease of IL-4, IL-5, IL-10, and IL-13, a trend of increase of TGF- $\beta$ (not significant), and, in the bronchoalveolar lavage, a dramatic decrease of eosinophils.

EPIT and SLIT decreased the Penh values in the same proportions, from the lowest dose of methacholine $(10 \mathrm{mg} /$ $\mathrm{mL}$ to the highest $40 \mathrm{mg} / \mathrm{mL}$ ). However, if EPIT improved Penh in all mice, SLIT did not in 2 mice. This resulted in the fact that Penh AUC values after EPIT returned to values similar to these of control mice, which was not seen with SLIT $(P<0.05$ versus controls).

In this study, EPIT and SLIT were given once a week at the same dose, that is, $100 \mu \mathrm{g}$ of pollen proteins, containing $5 \mu \mathrm{g}$ of the major allergen Phlp5, the effective dose described by Brimnes et al. in their murine model [6]. Anesthesia probably allowed better contact of allergen with the mucosa, by inhibiting swallowing. The efficacy of SLIT for all the study parameters appeared to be better than that previously published by Brimnes et al. [6], despite lower dose and frequency of administration.

The mechanistic reasons why EPIT and SLIT exhibited differences in the different studied parameters lack clarity. Whereas EPIT specifically targets the immune cells of the superficial layers of the skin, particularly skin Langerhans cells (LCs), SLIT targets dendritic cells (DCs) of the oral mucosa. We have demonstrated in another study with ovalbumin conjugated to fluorochrome that the allergen was detected in the superficial layers of the skin. Of note is that, within the first 24 hours following application, the allergen was only found in the antigen presenting cells, and more particularly in more than $90 \%$ of the LC of the epidermis and almost $50 \%$ of the dermal DC of the dermis [19]. After having captured allergen following epicutaneous or sublingual administration, DCs migrate to draining lymph nodes and stimulate lymphocytes. As suggested in studies by Strid et al., these cells may play a key role by influencing the immune profile of the reaction [20-22]. We have demonstrated that EPIT may be able to strongly influence both the migration of LC to the lymph node and lymphocytes stimulation [19]. Even if classic skin and oral LC show similar kinetics of migration to lymph nodes, they differ phenotypically and functionally [27]. In addition, the number of DC migrating from the skin is higher than from the buccal mucosa [28]. These data may explain part of the differences observed between EPIT and SLIT.

Senti et al. [7] recently described the epicutaneous administration of specific grass pollen allergens in patients with seasonal rhinitis. This pilot study suggested that immunotherapy could occur successfully via the skin route with repeated and prolonged applications of the allergen to the skin. A pilot study was also conducted in children with IgEmediated cow's milk allergy [8]. As the method used in that clinical study does not need any skin preparation, by contrast to that described by Senti et al. [7], it is our experience that it was very well tolerated in children.

\section{Conclusions}

In conclusion, these data suggest that the epicutaneous route might be at least as potent as the sublingual route for immunotherapy in an animal model. The immune mechanisms involved in this therapeutic process need further investigation but these data confirm that EPIT may represent a promising new route for immunotherapy, alternative to the sublingual route of administration.

\section{Abbreviations \\ AHR: Airway hyperresponsiveness \\ BAL: Bronchoalveolar lavage \\ CMC: Carboxymethyl cellulose \\ DC: Dendritic cells \\ EDS: Epicutaneous delivery system \\ EPIT: EPicutaneous immunotherapy \\ LC: Langerhans cells \\ Penh: Enhanced pause \\ SLIT: SubLingual immunotherapy.}

\section{Acknowledgments}

Acknowledgments are addressed to Dr. Micheline Lagranderie for her support in performing plethysmography and BAL fluid analyses. The authors would like to thank the staff of the animal facility of Paris XI University, School of Pharmacy, for the animal care and Dr. Guillaume Hébert, from SC Partners, for his editorial assistance. This study was supported by DBV Technologies, owner of the Viaskin ${ }^{\circledR}$ technology. LM, VD, ML, VD, and EP are DBV Technologies employees. PHB and CD have received honoraria from DBV Technologies with regards to the present study.

\section{References}

[1] S. R. Durham, S. M. Walker, E. M. Varga et al., "Long-term clinical efficacy of grass-pollen immunotherapy," New England Journal of Medicine, vol. 341, no. 7, pp. 468-475, 1999.

[2] J. Bousquet, R. Lockey, and H. J. Malling, "Allergen immunotherapy: therapeutic vaccines for allergic diseases-a WHO position paper," Journal of Allergy and Clinical Immunology, vol. 102, no. 4, part 1, pp. 558-562, 1998.

[3] T. Werfel, "Epicutaneous allergen administration: a novel approach for allergen-specific immunotherapy?" Journal of Allergy and Clinical Immunology, vol. 124, no. 5, pp. 1003-1004, 2009.

[4] G. W. Canonica and G. Passalacqua, "Sublingual immunotherapy in the treatment of adult allergic rhinitis patients," Allergy, vol. 61, no. 81, pp. 20-23, 2006.

[5] D. R. Wilson, M. T. Lima, and S. R. Durham, "Sublingual immunotherapy for allergic rhinitis: systematic review and meta-analysis," Allergy, vol. 60, no. 1, pp. 4-12, 2005.

[6] J. Brimnes, J. Kildsgaard, H. Jacobi, and K. Lund, "Sublingual immunotherapy reduces allergic symptoms in a mouse model 
of rhinitis," Clinical and Experimental Allergy, vol. 37, no. 4, pp. 488-497, 2007.

[7] G. Senti, N. Graf, S. Haug et al., "Epicutaneous allergen administration as a novel method of allergen-specific immunotherapy," Journal of Allergy and Clinical Immunology, vol. 124, no. 5, pp. 997-1002, 2009.

[8] C. Dupont, P. H. Benhamou, P. Soulaines, S. Morillon-LeGoue, N. Donne, and H. Piloquet, "Epicutaneous immunotherapy in severe cow milk allergy: a double blind pilot trial," Journal of Allergy and Clinical Immunology, vol. 123, no. 2, p. S183, 2009.

[9] L. Mondoulet, V. Dioszeghy, M. Ligouis, V. Dhelft, C. Dupont, and P. H. Benhamou, "Epicutaneous immunotherapy on intact skin using a new delivery system in a murine model of allergy," Clinical and Experimental Allergy, vol. 40, no. 4, pp. 659-667, 2010.

[10] N. Kalach, P. Soulaines, D. de Boissieu, and C. Dupont, "A pilot study of the usefulness and safety of a ready-to-use atopy patch test (Diallertest) versus a comparator (Finn Chamber) during cow's milk allergy in children," Journal of Allergy and Clinical Immunology, vol. 116, no. 6, pp. 1321-1326, 2005.

[11] W. O. Caster, A. B. Simon, and W. D. Armstrong, "An Evans blue method for the determination of plasma volume in the soft tissues of the rat," Journal of Applied Physiology, vol. 6, no. 11, pp. 724-726, 1954.

[12] E. Hamelmann, J. Schwarze, K. Takeda et al., "Noninvasive measurement of airway responsiveness in allergic mice using barometric plethysmography," American Journal of Respiratory and Critical Care Medicine, vol. 156, no. 3, pp. 766-775, 1997.

[13] J. A. J. Vanoirbeek, V. De Vooght, H. M. Vanhooren, T. S. Nawrot, B. Nemery, and P. H. M. Hoet, "How long do the systemic and ventilatory responses to toluene diisocyanate persist in dermally sensitized mice?" Journal of Allergy and Clinical Immunology, vol. 121, no. 2, pp. 456-463, 2008.

[14] A. J. M. Van Oosterhout, B. Van Esch, G. Hofman et al., "Allergen immunotherapy inhibits airway eosinophilia and hyperresponsiveness associated with decreased IL- 4 production by lymphocytes in a Murine model of allergic asthma," American Journal of Respiratory Cell and Molecular Biology, vol. 19, no. 4, pp. 622-628, 1998.

[15] L. Conejero, Y. Higaki, M. L. Baeza, M. Fernández, I. VarelaNieto, and J. M. Zubeldia, "Pollen-induced airway inflammation, hyper-responsiveness and apoptosis in a murine model of allergy," Clinical and Experimental Allergy, vol. 37, no. 3, pp. 331-338, 2007.

[16] M. Lagranderie, M. Abolhassani, J. Vanoirbeek et al., "Mycobacterium bovis BCG killed by extended freeze-drying reduces airway hyperresponsiveness in 2 animal models," Journal of Allergy and Clinical Immunology, vol. 121, no. 2, pp. 471-478, 2008.

[17] J. M. Spergel, E. Mizoguchi, J. P. Brewer, T. R. Martin, A. K. Bhan, and R. S. Geha, "Epicutaneous sensitization with protein antigen induces localized allergic dermatitis and hyperresponsiveness to methacholine after single exposure to aerosolized antigen in mice," Journal of Clinical Investigation, vol. 101, no. 8, pp. 1614-1622, 1998.

[18] L. Mondoulet, V. Dioszeghy, J. A. J. Vanoirbeek, B. Nemery, C. Dupont, and P. H. Benhamou, "Epicutaneous immunotherapy using a new epicutaneous delivery system in mice sensitized to peanuts," International Archives of Allergy and Immunology, vol. 154, no. 4, pp. 299-309, 2010.

[19] V. Dioszeghy, L. Mondoulet, V. Dhelft, C. Dupont, and P. H. Benhamou, "Epicutaneous immunotherapy, application of allergen on intact skin result on rapid uptake by the dendritic cells in sensitized mice," in Proceedings of the EEACI Congress, 2009.

[20] J. Strid, R. Callard, and S. Strobel, "Epicutaneous immunization converts subsequent and established antigen-specific $\mathrm{T}$ helper type 1 (Th1) to Th2-type responses," Immunology, vol. 119, no. 1, pp. 27-35, 2006.

[21] J. Strid, J. Hourihane, I. Kimber, R. Callard, and S. Strobel, "Epicutaneous exposure to peanut protein prevents oral tolerance and enhances allergic sensitization," Clinical and Experimental Allergy, vol. 35, no. 6, pp. 757-766, 2005.

[22] J. Strid, M. Thomson, J. Hourihane, I. Kimber, and S. Strobel, "A novel model of sensitization and oral tolerance to peanut protein," Immunology, vol. 113, no. 3, pp. 293-303, 2004.

[23] M. Calderon, R. Mösges, M. Hellmich, and P. Demoly, "Towards evidence-based medicine in specific grass pollen immunotherapy," Allergy, vol. 65, no. 4, pp. 420-434, 2010.

[24] A. Razafindratsita, N. Saint-Lu, L. Mascarell et al., "Improvement of sublingual immunotherapy efficacy with a mucoadhesive allergen formulation," Journal of Allergy and Clinical Immunology, vol. 120, no. 2, pp. 278-285, 2007.

[25] G. D’Honneur, J. M. Rimaniol, A. El Sayed, Y. Lambert, and P. Duvaldestin, "Midazolam/propofol but not propofol alone reversibly depress the swallowing reflex," Acta Anaesthesiologica Scandinavica, vol. 38, no. 3, pp. 244-247, 1994.

[26] M. Torres Lima, D. Wilson, L. Pitkin et al., "Grass pollen sublingual immunotherapy for seasonal rhinoconjunctivitis: a randomized controlled trial," Clinical and Experimental Allergy, vol. 32, no. 4, pp. 507-514, 2002.

[27] J. P. Allam, N. Novak, C. Fuchs et al., "Characterization of dendritic cells from human oral mucosa: a new Langerhans' cell type with high constitutive FceRI expression," Journal of Allergy and Clinical Immunology, vol. 112, no. 1, pp. 141-148, 2003.

[28] N. Chalermsarp and M. Azuma, "Identification of three distinct subsets of migrating dendritic cells from oral mucosa within the regional lymph nodes," Immunology, vol. 127, no. 4, pp. 558-566, 2009. 


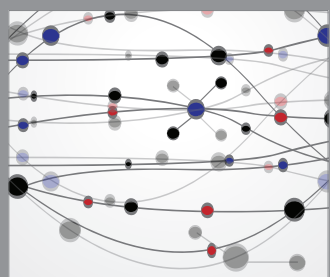

The Scientific World Journal
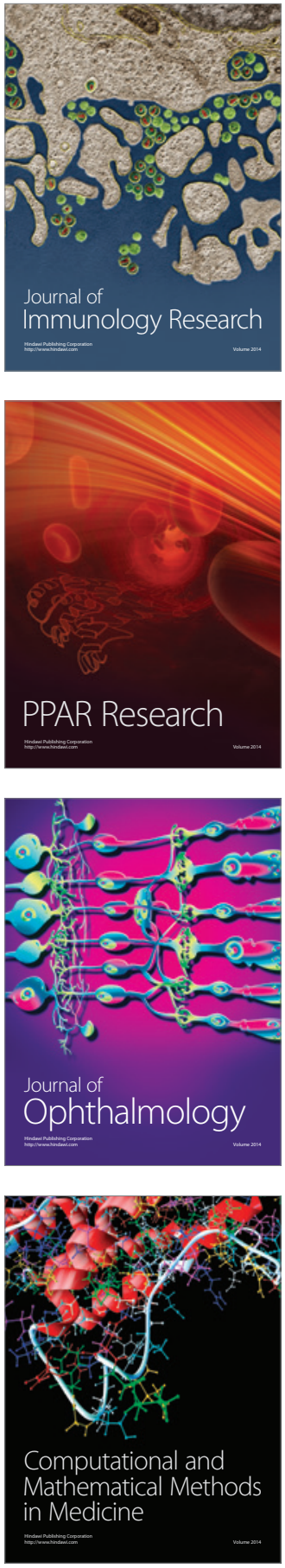

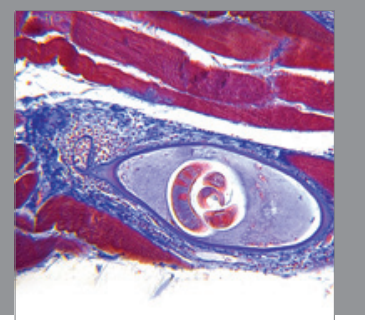

Gastroenterology

Research and Practice
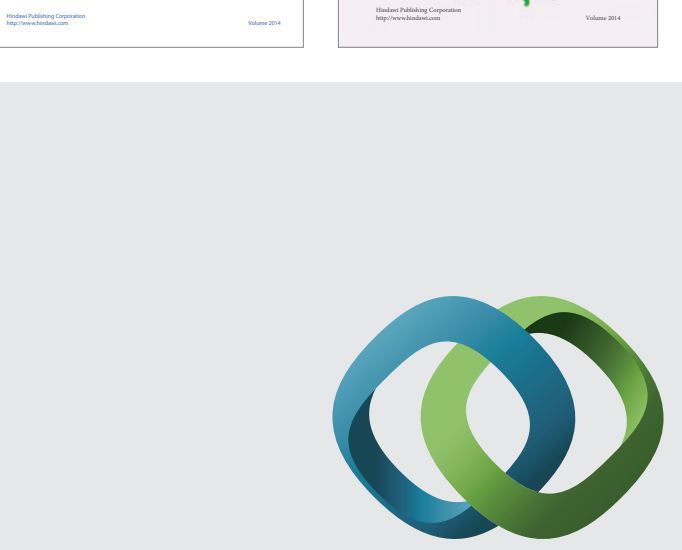

\section{Hindawi}

Submit your manuscripts at

http://www.hindawi.com
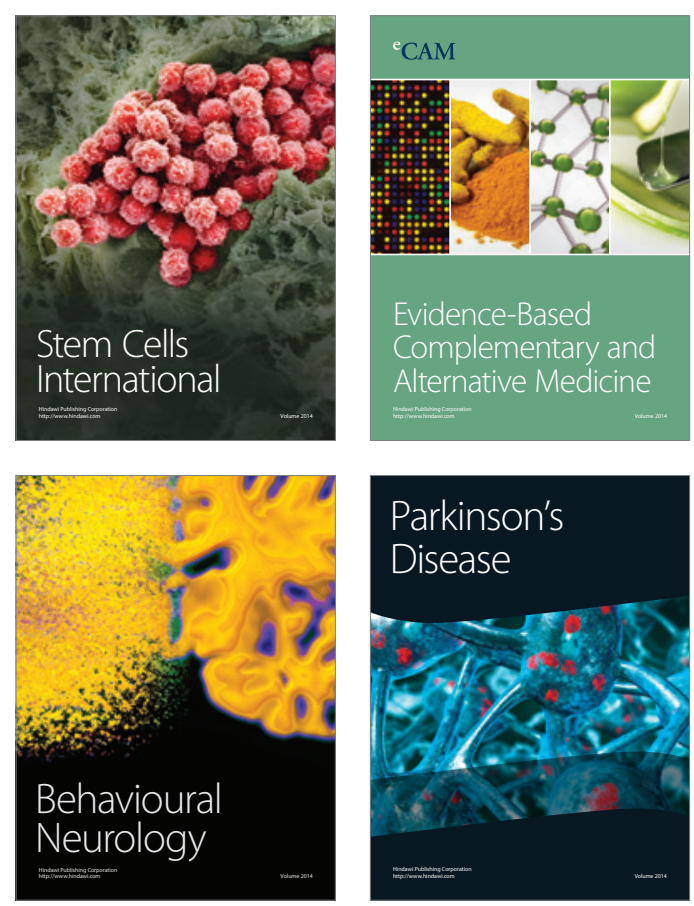

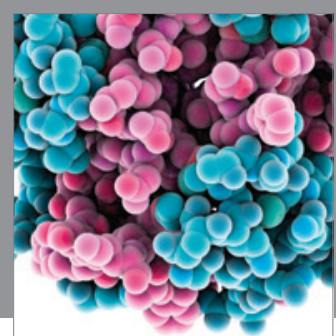

Journal of
Diabetes Research

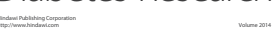

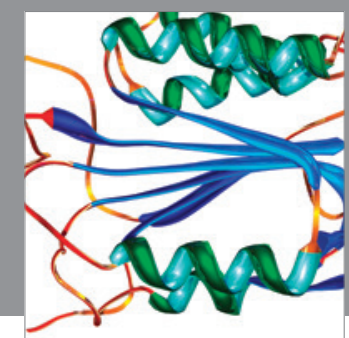

Disease Markers
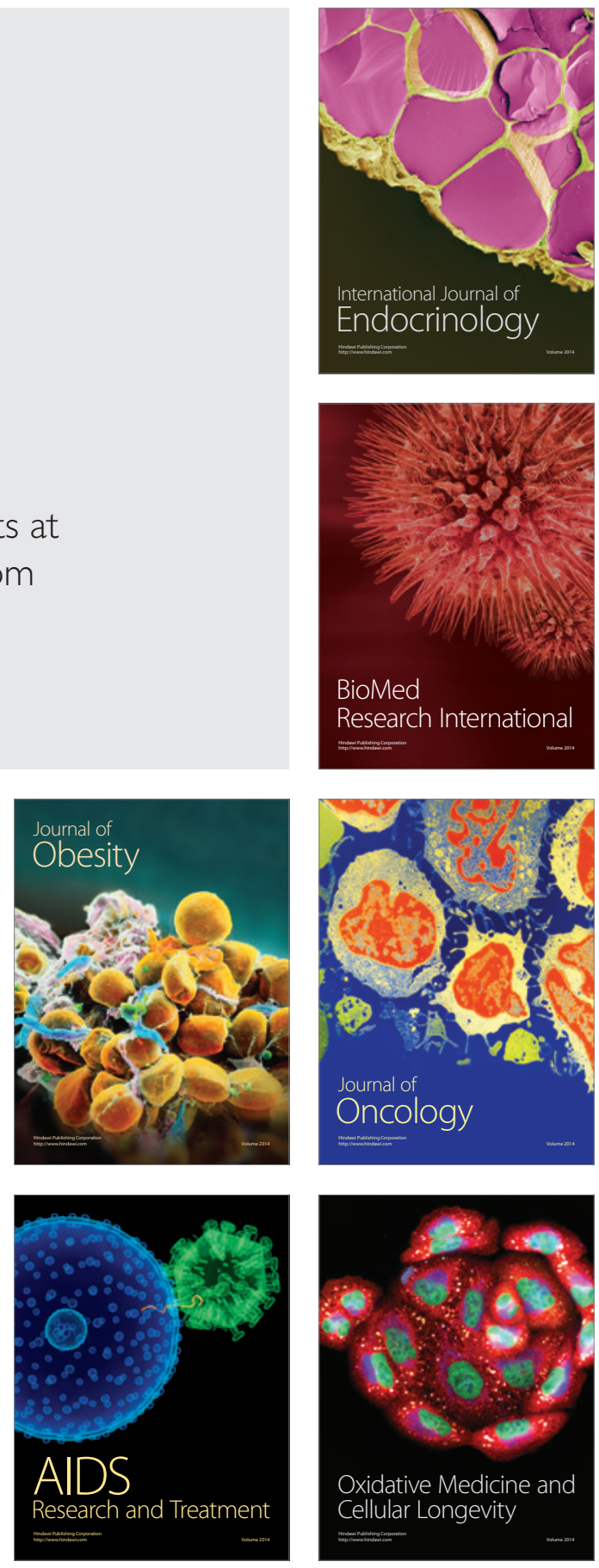